\title{
Speciation of ultra-trace mercury(II) in natural waters: Insights from a DNA-based biosensor and hydrochemical modeling
}

\author{
KUNFU PI ${ }^{1}$, JUEWEN LIU ${ }^{2}$ AND PHILIPPE VAN \\ CAPPELLEN $^{2}$ \\ ${ }^{1}$ China University of Geosciences \\ Presenting Author: pikunfu@cug.edu.cn
}

${ }^{2}$ University of Waterloo

An understanding of the speciation of aqueous mercury(II), in addition to its total concentration, is of vital importance to elucidate the mobility, cycling and toxicity of mercury $(\mathrm{Hg})$ in the environment [1], and assess the risks to ecosystems and drinking water sources. Research on $\mathrm{Hg}$ biogeochemistry, however, is hindered by the lack of sensitive and reliable detection methods that can measure trace-level $\mathrm{Hg}$ (II) directly on site and in situ. Unravelling the fate of $\mathrm{Hg}$ in remote regions also calls for field-deployable sensing tools that are easy to operate and can reveal $\mathrm{Hg}$ (II) speciation in variable aquatic environments [2].

In a previous study [3], we presented a DNA-DGT sensor for aqueous $\mathrm{Hg}(\mathrm{II})$ that combines the DNA-functionalized biosensing material with the Diffusive Gradients in Thin Films (DGT) technique. Here we show that the sensor can detect ultratrace $\mathrm{Hg}(\mathrm{II})$ concentrations in hydrochemically diverse groundwaters and surface waters by adjusting the deployment time of the sensor. Quantification of aqueous $\mathrm{Hg}(\mathrm{II})$ speciation with the sensor, combined with temperature-calibrated hydrochemical models, indicates that the (in-situ) water temperature and dissolved organic matter (DOM) concentration strongly affect the partitioning of aqueous $\mathrm{Hg}(\mathrm{II})$ between inorganic and organic species, which in turn affects its bioavailability. Furthermore, DNA-DGT sensor data, when interpreted along with additional results from laboratory-based hydrochemical analyses, suggest that the mobilization of $\mathrm{Hg}(\mathrm{II})$ is linked to the biogeochemical cycling of sulfur in groundwater systems.

[1] Ullrich et al. (2001) CREST 31, 241-293. [2] Douglas et al. (2012) ENVIR CHEM 9, 321-355. [3] Pi et al. (2020) ES\&T 54, 13680-13689. 